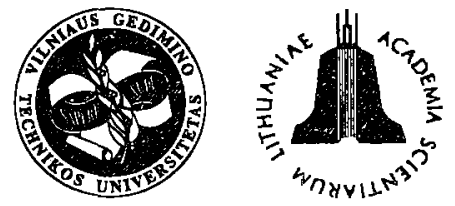

ISSN 1648-4142 TRANSPORT

http:/www.vtu.lt/english/editions

TRANSPORT - 2003, Vol XVIII, No 1, 40-48

\title{
ANALYSIS OF WEARING-OUT CAUSES FOR REVOLVING-BLADE MIXERS AND THEIR RELIABILITY IMPROVEMENT
}

\author{
Jurgis Jurevičius' ${ }^{1}$, Henrikas Sivilevičius ${ }^{2}$, Bronislovas Spruogis ${ }^{3}$ \\ Dept of Transport Technology Equipment, Vilnius Gediminas Technical University, \\ Plytines g. 27, LT-2016 Vilnius, Lithuania. Tel.: (+370 5) 2744783, fax: (+370 5) 2745060
}

Received 200207 11; accepted 20021221

\begin{abstract}
In road coverings and structures of transport infrastructure, composite mixes of various compositions are used made with either organic or mineral binding agents. Most often they are made in a discreet revolving-blade forced mixer, and the final product quality is subject to the mixer construction and parameters. The present paper analyzes wear causes of a revolving-blade mixer with the most important of them - sticking of grains between the blade end and the bottom. Forces are defined effecting various-sized grains found between the blade end and the mixer bottom. Mixer quality assessment methodology is presented, based on analysis principles of homogeneity dynamics for mix being made by it. It is demonstrated that construction homogeneity estimates are different for mixers with various wearing-out levels. Wearing-out of mixer elements may be reduced and mixing quality for mix may be improved by choosing the optimum distance between the blade end and the bottom fretting and changing blade metal and dimensions. Elastic centrifugal coupling is recommended to decrease transmission strokes.
\end{abstract}

Keywords: revolving-blade mixer; grain sticking, wear, mix homogeneity; elastic centrifugal coupling; reliability improvement.

\section{Introduction}

For the construction of transportation road coverings and their structures (bridges, viaducts, scaffold bridges, passenger stations, terminals, etc.) various mixes made with either mineral or organic binding agents are used. Such mixes ascribed to composites are composed of several mineral substances consisting of grains with various coarseness, form and hardness, which substances are cemented into conglomerate with bitumen, tar, cement, lime, polymer or other binding agents. Any mix under production to be used for the installation of road pavement or layers of its construction, for manufacture of concrete or reinforced concrete elements, shall have mineral materials and binding agent in the amounts corresponding to its composition design values. These mix constituents shall be uniformly distributed, i.e., the mix must be homogeneous. Only an installed of transport layer or structure element made with quality materials of optimum composition and with suitably mixed components may be strong, durable and meet the design operation characteristics.

Mixes used for laying of transport infrastructure elements, their reconstruction, repairs or construction are

\footnotetext{
'E-mail: tti@ti.vtu.lt

${ }^{2} \mathrm{E}$-mail: henrikas@ti.vtu.lt

3E-mail: tti@ti.vtu.lt
}

produced in fixed or mobile devices - asphalt concrete and cement concrete mixing machines. Any mixing machine has a mixer in which pretreated (dried, heated, sieved, dozed) substances are mixed. Substance mixing operation is the final part of the entire technological process and the quality of the final mix is highly subject to performance quality of the operation.

Mix is most often produced in a periodic forced mixer. Mixer dimensions, construction, shaft rotation speed, number of blades and their location, inclination angle, form, distance from the box (body) walls and other construction and technological parameters must be such that all mix components are fully mixed (uniformly distributed throughout the mix) within as short mixing time as possible. This property is necessary to be maintained under mixer operation when its all elements are constantly affected by wear. Under intensive wear of separate mixer elements (blades, fretting, blade holders, bolt, shafts) its operation parameters change. Upon increase of the gap between the blade end and the mixer body fretting, grains of various sizes get into the gap and get stuck and crushed, thus increasing power consumption, intensifying wear of the device elements and decreasing substance mixing quality.

Scientific quality assessment works for asphalt-concrete mix process intensification, for mixer construction improvement and substance mixing have demonstrated that $[1-10]$ this technological operation is extremely com- 
plex. Mixing process is of the determined stochastic nature, thus it may be suitably managed only after in-depth studies of kinetics of this process and factors determining not only mixer durability, but mix homogeneity, as well. Neither scientists, nor producers have a unanimous opinion on which parameters should be used to assess homogeneity of produced mix and how this mixing-up quality indicator changes with time, upon wear of mixer elements and use of various materials. The most recent foreign scientists' research $[11-18]$ has demonstrated that currently urgent questions of mix composition theory, methodology of substance mixing-up quality assessment and mixing device reliability improvement are not fully answered.

The purpose of the paper is to present, after theoretic analysis of wearing-out causes for periodic revolving-blade forced mixers, ways to improve mixer reliability and propose a universal mixing-up quality assessment methodology allowing to compare, on its basis, mixers of various construction and of various technical condition.

\section{Wearing-Our Causes for Revolving-Blade Mixers}

In periodic asphalt concrete mixing machines mix is made in individual portions (mixtures), which are regularly discharged from the mixer. The mixer operating cycle consists of technological operations performed according to a specified sequence (Fig 1). The lowest moment needed to rotate an empty mixer is $M_{0}$. After loading it with dry hot mineral substances (MM) and adding bitumen afterwards, the moment of resistance to rotate mixer shafts increases to $M_{\max }$. After mixing-up of asphalt concrete mix (ABM) is completed and upon unloading this mixture from the mixer torsion moment rapidly decreases from $M_{\max }$ to $\mathrm{M}_{0}$. Due to grain sticking between blade ends and mixer bottom the torsion moment change of stochastic nature is not performing according to smooth linear functions. Its pulsation should be minimum in each segment of cycle-gram thus reducing dynamic loads emerging in mixer transmission and prolonging machine shelf life.

Revolving-blade cyclic mixers are highly power-consumptive. Power consumption is caused by high loads affecting revolving-blade mixer elements and it intensively increases wearing-out of their surfaces and reduces mixer reliability. The basic revolving-blade mixer wearing-out causes are the following:

- Loads emerging during transmission start. During transmission start the torsion moment increases up to 2,5 times of the nominal torsion moment or even higher. In such case the mixer transmission and shaft bearings are intensively loaded and critical tensions of individual mixer units and parts emerge, which tensions intensively increase wearing-out and reduce mixer reliability [2-4];

- Occurrence of accidental hard elements together with mixing substance. Occurrence of hard grains (metal fractions, etc.) in the mixer causes impact loads, which cause break-ups of individual mixer elements, motor overload and burning of its windings (in case of an electric motor) or sticking of mixer blades. This reduces mixer reliability [5-8];

- Intensive wearing-out of blades and bottom wearing-out. When crushing and grinding coarse fraction mix grains the mixer blades and bottom are deteriorating very intensively $[7-10]$.

The first two types of causes are widely analyzed in the above specified technical publications. The third type of causes is specific, therefore we will go into more details.

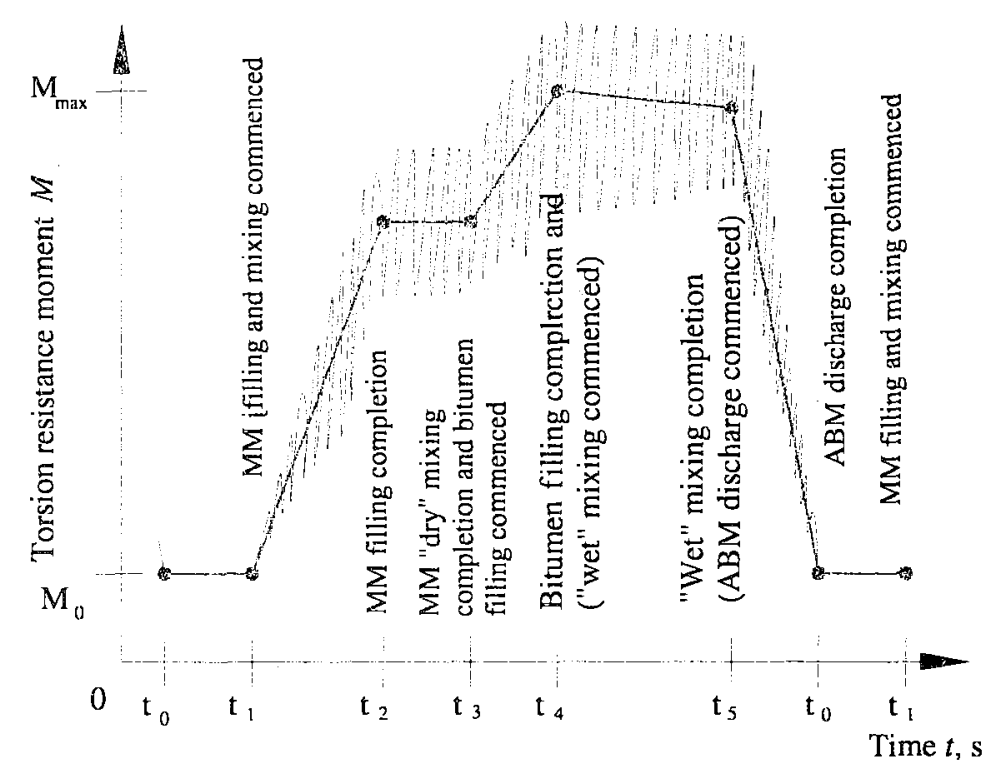

Fig 1. Change scheme of resistance moment $M$ affecting transmission of constantly rotating periodic forced mixer performing working regime operations 


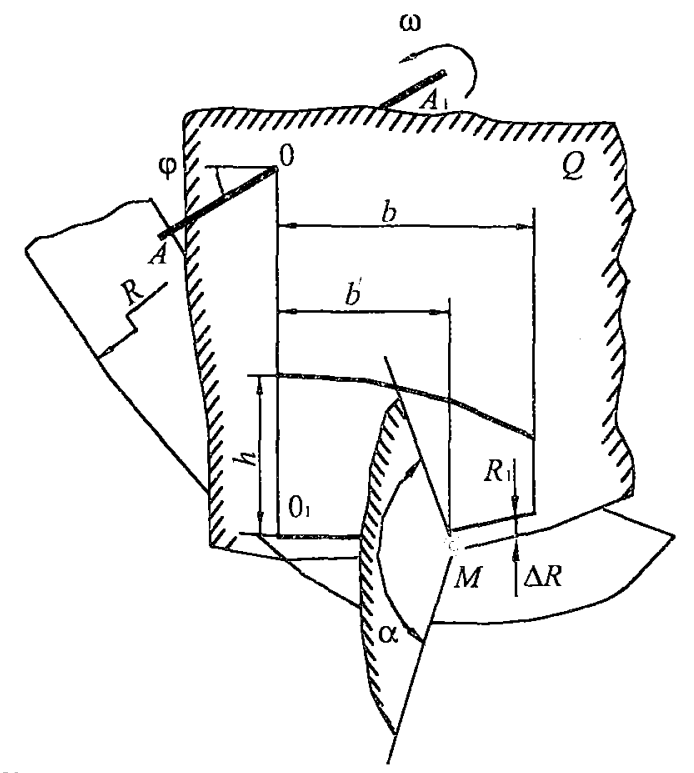

Fig 2. Determination scherne for grain grabbing angle by a mixer blade during substance mixing

Mineral substance grains get stuck and are getting finer between blades and cylinder surface of the mixer bottom and in the keel zone formed by side and end edges of blades. When selecting mixer parameters such conditions may be created under which grains will not get stuck and therefore overloads of mixer working instruments will not occur and granulometric composition of mix produced will not be essentially changed [9].

Conditions will be determined under which hard grains get stuck between a rotating blade and the cylinder surface of the mixer bottom (Fig 2). The blade surface may be analyzed as a constituent of moving surface $Q$, which constituent rotates around the axis $\mathrm{AA}_{1}$ at a constant angular speed $\omega$.

Inclination angle $\varphi$ of the surface Q (angle of blade fastening) remains unchanged. It was analytically determined that sticking angle $\alpha$, at which hard grain $M$ is grabbed by the blade and slowly moves along the mixer surface, is calculated by the formula:

a)

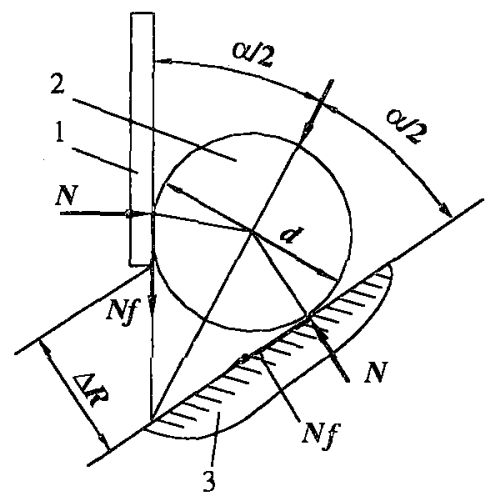

$$
\alpha=2 \operatorname{arctg} \sqrt{\frac{R-b^{\prime} \sin \varphi \cos \varphi}{R-b^{\prime} \sin \varphi \cos \varphi}},
$$

$R$ - cylinder surface radius of the mixer bottom; $b^{\prime}$ distance between the grain $M$ and geometric radius of the blade $R_{1}=00_{1}$.

The condition of grain sticking between the blade attacking surface and the bottom surface is proposed to be put down in the following form (Fig 3, a).

$$
-2 N \sin \frac{\alpha}{2}+2 N f \cos \frac{\alpha}{2}+F \geq 0,
$$

from which the following is derived

$$
\alpha \leq 2\left[\rho+\arcsin \left(\begin{array}{c}
F \\
2 N
\end{array} \cos \rho\right)\right] \text {, }
$$

$N$ - the force by which the grain is pressed between the blade attacking surface and the bottom surface $\mathrm{N} ; F-$ resultant force of mix forces affecting the grain; $f$-grain and blade or bottom surfaces friction rate $f=\operatorname{tg} \rho ; \rho-$ friction angle in degrees.

The grain mass influence on sticking is low compared with $N$ and $F$ forces, therefore it is not taken into account in formulae (2) and (3). When $F=0$, the sticking angle is found to be $\alpha \geq 2 p$. The final inequation determines $\alpha$ values at which grains get stuck between the blade and mixer bottom surfaces even in cases when there is no force $F$ holding grains in the grabbing angle zone.

Grains may get stuck between the blade and the mixer bottom surfaces, if their diameter $d$ does not allow them to get closer to the external end edge of the blade [9]. In such case:

$$
d>\frac{2 \Delta R}{1+\cos \alpha},
$$

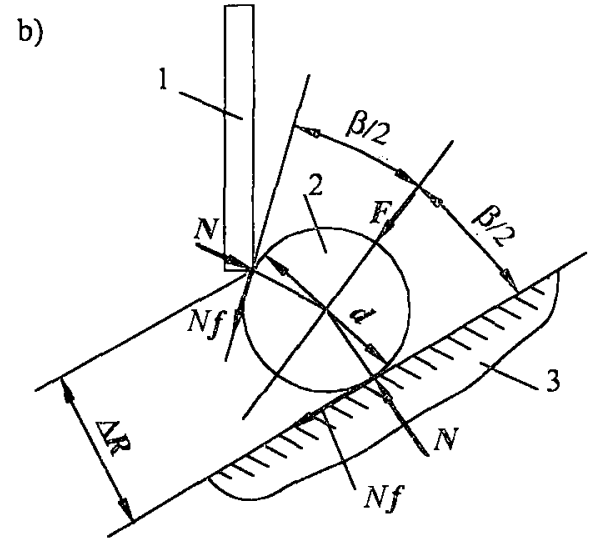

Fig 3. Scheme of forces affecting hard grains when they get stuck: a - between the mixer bottom and the attacking blade surface; $\mathrm{b}$ - between the mixer bottom and the blade side edges; 1 -blade; 2 - hard grain; 3 - mixer bottom 
$\Delta R$ - gap between the bottom surface and the end edge of the blade.

When

$$
\Delta R<d \leq \frac{2 \Delta R}{1+\cos \alpha},
$$

grains may touch with the end edge of the blade. Then grains will get stuck in the gap DR between the mixer bottom and the end of blade edge. Then grain sticking condition may be put down (2) in the form of inequation, when $a=b$, here $b$ - grain grabbing angle between the blade end edge and the mixer bottom surface (Fig 3,b). The following is found out from geometric expressions

$$
\operatorname{tg} \frac{\beta}{2}=\sqrt{\frac{d}{\Delta R}}-1
$$

Using this expression the following is obtained from the inequation (2)

$$
\begin{array}{r}
d \leq \frac{\Delta R}{A^{2}}\left[-A\left(1-f^{2}\right)+2 f \sqrt{(A+1)\left(f^{2}-A\right)}\right], \quad \text { (7) } \\
A=\left(\frac{F}{2 N}\right)^{2}-1-\text { non-dimensional value, which takes into }
\end{array}
$$

account influence of $F$ and $N$ forces to the diameter of sticking grains.

(7) inequation determines the top limit value of grain dimension size, which grains get stuck between the external blade edge and the mixer bottom surface. Their bottom limit determined from the condition of grain grabbing by the blade end edge: $d>\Delta R$. The following is obtained from the inequation (7), when $F=0$ and the last inequation:

$$
\Delta R\left(f^{2}+1\right)>d>\Delta R .
$$

From expression (8) grain dimension interval may be determined, which grains get stuck between the external blade edge and the mixer bottom surface, even under 0 effect of $F$ force, pressing grains to blade end gaps.

The obtained dependencies allow to determine grabbing angle of hard grains at various blade mounting angles and at various widths, allow to find out limit grabbing angles at which grains get stuck, as well as calculate grain dimensions, which get stuck at blade ends.

The mix quality (homogeneity) and mixing time are subject to intensiveness of masses' change between individual parts of mixture throughout the entire mixer volume. Transversal and longtitudinal mixer-wise movement of mix flows is subject to impulses of forces, which through blades are transmitted to mix grains. Taking these impulses into account the recommended [9] blade mounting angle is $\varphi=45^{\circ}$, and their width - $b=0,57 R$ (Fig 2), here $R=R_{1}+\Delta R$. Dimensions at blade ends need further specification.

Fig 4 illustrates the dependency of grain grabbing

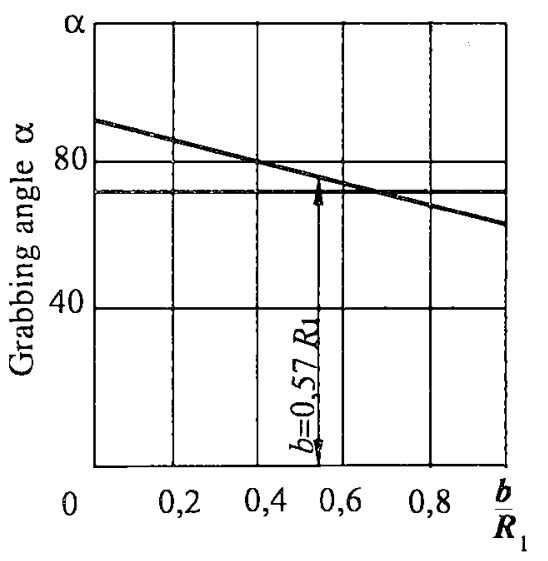

Fig 4. Dependency of the grain grabbing angle upon the ratio of the blade width its radius, when $\varphi=45^{\circ}$

angle $\alpha$ upon the ratio of blade width $b$ and radius $R_{1}$ [9]. The value of this angle is determined according to equation ( 1 ), when $\varphi=45^{\circ}$. At constant radius $R_{1}$, but increasing blade width $b$, the grabbing angle $\alpha$ is reduced coming closer to the intersection point of blade attacking and side surfaces. Then the grain sticking condition becomes more favorable and blade longtitudinal wearing-out is higher at the attacking edge.

The angle of grain friction to the blade surface and the mixer bottom reaches up to $p=35^{\circ}$. According to formula (3) it is obvious that when the blade width is $b=0,57 R$, low strength $(\sigma=35 \mathrm{MPa})$ coarse crushed stone will be crushed at pressure force between the blade and the mixer bottom of $F \geq 640 \mathrm{~N}$. This force significantly exceeds the impact of mix mass to the grain and mostly affects grains of $20-40 \mathrm{~mm}$ diameter. Defining force $F$ is quite complicated. Grains satisfying inequation (8) get stuck in the end gaps of blades even without any impact of force $F$. During mixing, the mix mass affects grains and presses them to blades and the mixer bottom. Therefore real dimensions of sticking grains exceed $d=\Delta R\left(f^{2}+1\right)$.

Because of wear of blade ends the gap between them and the mixer bottom increases, maximum grain dimensions increase, which grains get stuck between the blade ends and the mixer bottom, therefore blades are heavier loaded.

Hard mix grains may be grouped in to the following groups by dimensions [9]:

the first, when $d<\Delta R$;

the second, when $\Delta R<d<\Delta R\left(f^{2}+1\right)$;
the third, when $d>\Delta R\left(f^{2}+1\right)$.

The first group grains may not get stuck in gaps between ends and the mixer bottom. When gaps exceed maximum grain dimensions $\mathrm{d}>40 \mathrm{~mm}$ the zone forms between blade ends and the mixer bottom, where blade impact on mix is low. If grains of the second group dimen- 
sions occur in gaps, they get stuck there even when they are not affected by the mix mass. Grains of this group get stuck at any blade rotation speeds $\nu>0$.

Blade end linear speed has the highest impact on sticking and crishing of the third group grains. This mix impact is transmitted to grains in the zone between the blade ends and the mixer bottom. Test determined [9] that this gap was $12 \mathrm{~mm}$. Grain dimensions of the third dimension group were $\mathrm{d}>18 \mathrm{~mm}$.

It has been determined [10] that with increasing blade rotation linear speed $v$ grain crushing intensiveness also grows due to impact of centrifugal forces. When making coarse-grained mixes (when $\nu>2,8 \mathrm{~m} / \mathrm{s}$ ) mixer operation gets complicated because of body deformations, blade breaks, which are not observed at mixing of fine-grained mixes.

Partial crushing of crushed stone coarse fraction takes place when it is pressed with $12-20 \mathrm{kN}$ force. Therefore bottom, bolt and blades need to be reinforced for mixers working at a speed exceeding $v>2,8 \mathrm{~m} / \mathrm{s}$.

Tests confirmed that blade inclination angle $\varphi=45^{\circ}$ and width $b=0,57 R$, are selected to have optimum mix quality and mixing time. In addition such construction is reasonable in respect of grain sticking, as well. Beside this, according to grain sticking condition, gaps between blade ends and the mixer bottom shall be minimum.

The performed analysis of wear causes for revolving-blade mixers demonstrates that blades are most often replaced compared to other mixer elements, and need to be replaced $2 \ldots 3$ times more frequently than other replacement elements. For example, asphalt concrete mixer blades of the ex-Soviet Union production plants were most often made of the chilled cast iron alloyed with $4,5 \ldots 6,5$ $\%$ chromium. Their surfaces are mostly affected by abrasive mix components. Under the effect of abrasive environment the geometry of biades changes. Average operation time of such blades does not exceed $850 \mathrm{~h}$ (approximately 16000 MT of ready-made mix). After this operation time the radial gap between the blade ends and the mixer bottom increases, therefore homogeneity indicators of mix produced get worse. Mixer idle time increases because deteriorated blades need replacement with new ones, thus reducing mixer economic efficiency and increasing operation costs.

To reduce or partially eliminate revolving-blade mixer wearing-out various construction and technological measures may be applied.

\section{Assessment of Substance Mixing-Up Quality and Its Change Upon Mixer Wearing}

The most important rechnological mixer quality indicator represents homogeneity of asphalt concrete or other mix produced by it, showing how unifornly all its components are distributed throughout the mixer. Homogeneity is not regulated by normative documents in force [19], therefore its minimum permissible value is unknown.
Most often norms only provide minimum permissible substance mixing time inside mixer determining homogeneity. Mixer construction, technical condition and technological indicators must be such that, after mixing dozed substances for sufficiently short time, average quadratic deviations of component quantities in mix $\sigma_{f i}$ are either close to zero or minimum. Average quadratic deviation $\sigma_{f i}$ of component $i$ quantity in mix is calculated according to the formula:

$$
\sigma_{f i}=\sqrt{\frac{\sum_{a=1}^{\mathrm{e}}\left(k_{f i a}-\bar{k}_{f i}\right)^{2}}{\mathrm{e}-1}},
$$

e - number of individual samples taken at random locations of the mix produced by the mixer; $k_{f i a}-$ actual quantity of component $i$ in mix sample No. $a, k_{f i}$ - arithmetical mean of actual quantity of component $i$ in mixture calculated according to the formula.

$$
k_{f i}=\frac{\sum_{a=1}^{\mathrm{e}} k_{f i a}}{\mathrm{e}}
$$

Homogeneity estimate of asphalt concrete mix according to average quadratic deviation for the component $i$ quantity is the function of mixing time $t_{m}$, mixer construction and technical condition $k$ and operating mode $d$, i.e., $\sigma_{f i}=f\left(t_{m}, k, d\right)$.

Upon the increase of mixing time of dozed mineral substances and bitumen mixed at a discretional forced mixer $t_{m}$ from 0 to $\infty$ seconds, at first average quadratic deviations of each component quantity in asphalt concrete mix $\sigma_{f i}$ rapidly reduce. After some-teens or some tens of seconds this reduction slows down till the mixing time $t_{m}$ is achieved, which, if further prolonged, almost does not increase mix homogeneity, as far as $\sigma_{f i}$ values almost do not reduce (Fig 5). We propose to name such homogeneity of asphalt concrete mix when the actual average quadratic deviation $\sigma_{f i k}$ of $i$ component quantity in mixture does not reduce at increasing substance mixing time $t_{m}$, as construction homogeneity. It differs for various components: for bitumen it is achieved upon the longest substance mixing time.

This theoretical dynamics is also confirmed by experiment data $[20,21]$ obtained after examining asphalt concrete mix made by asphalt concrete mixing machines of D-508-2A model ant other models (Table).

The highest quality is the quality of mixers with perfect construction, of technically good condition and operating under optimum mode (optimum volume filling with substances, suitable shaft speed, "dry" and ,wet" mixing time ratio, etc.) the operating dynamics of which is illustrated by Curve 1 (1) (Fig 5). It achieves the highest uniformity of $i$ component quantity evaluated by construction homogeneity estimate $\sigma_{f i k 1}$, obtained at the lowest mixing time of only $t_{n k 1}$ seconds. This lowest 
The influence of duration $t_{m}$ of asphalt concrete mixing in discrete forced mixing equipment on its homogeneity

\begin{tabular}{|c|c|c|c|c|c|c|}
\hline \multirow{2}{*}{$\begin{array}{l}\text { Asphalt concrete mix } \\
\text { component }\end{array}$} & \multirow{2}{*}{$\begin{array}{l}\text { Homogeneity } \\
\text { estimate } \\
\sigma_{j i} \%\end{array}$} & \multicolumn{2}{|c|}{$\begin{array}{l}\text { Of [20], when } t_{m}=30-240 \mathrm{~s} \text { by } \\
\text { taking by boggie up to } 48 \\
\text { samples from mixture }\end{array}$} & \multicolumn{3}{|c|}{$\begin{array}{l}\text { Of }[21] \text {, when } t_{m}=0-120 \mathrm{~s} \text { by taking } 8 \\
\text { mixture samples with a scoop sampler }\end{array}$} \\
\hline & & $t_{m}=30 \mathrm{~s}$ & $\begin{array}{l}\text { Lowest values at } \\
\text { long mixing }(>60 \mathrm{~s})\end{array}$ & $\begin{array}{l}\text { At "dry"(no } \\
\text { bitumen) } \\
\text { mixing for } 5 \mathrm{~s}\end{array}$ & $t_{m}=30 \mathrm{~s}$ & $\begin{array}{l}\sigma_{\text {vill }} \text { mixing } \\
\text { from } \\
30 \text { to } 120 \mathrm{~s}\end{array}$ \\
\hline Bitumen (B) & $\sigma_{f B}$ & 0,55 & 0,2 & - & 0,13 & 0,26 \\
\hline Mineral powder (MM) & $\sigma_{f M M}$ & 0,5 & 0,15 & 1,8 & 0,26 & 0,80 \\
\hline Crushed stone (SK) & $\sigma_{f S K}$ & 0,8 & 0,3 & 5,1 & 1,75 & 1,26 \\
\hline Sand (SM) & $\sigma_{f S M}$ & 0,9 & 0,3 & - & - & - \\
\hline
\end{tabular}

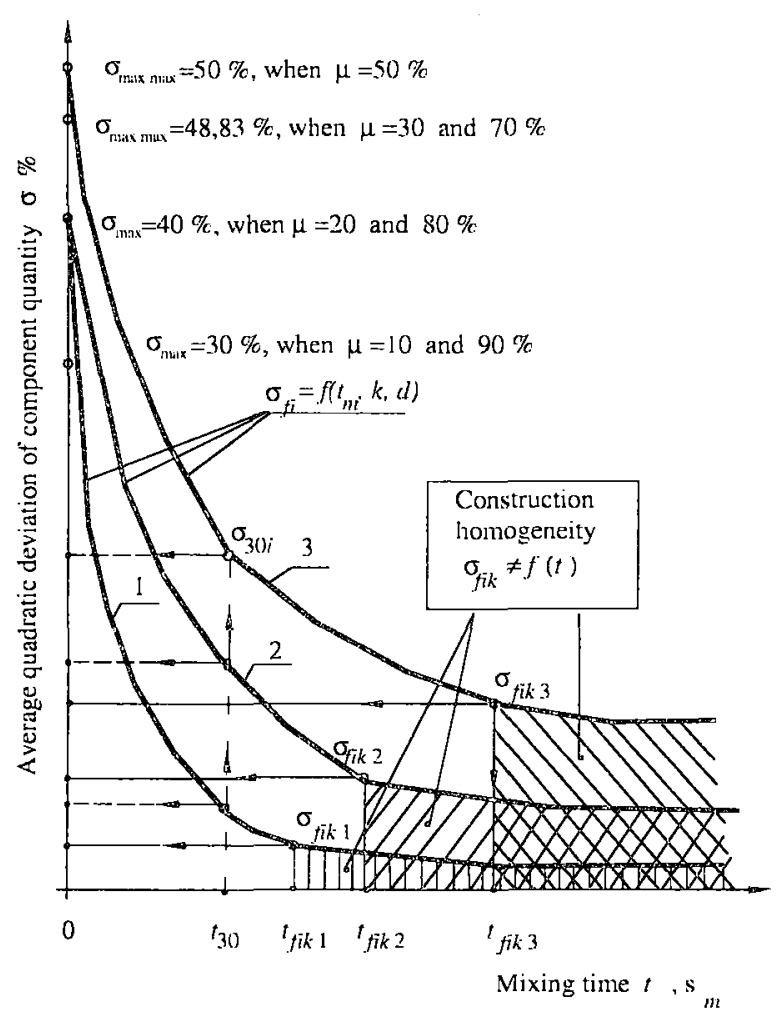

Fig 5. Stability change model of $i$ component quantity in asphalt concrete mixture made by different mixers

needed mixing time $t_{m k 1}$ may be even shorter than 30 seconds $\left(t_{30}\right)$, which is standardized by Construction Guidelines R 35-01 [19] as the lowest permissible mixing time. But most often it is misunderstood by producers, as far as it is considered to be an axiom without taking the mix type and grade, mixing machine module and mix mass into account. Construction homogeneity estimate for a perfect mixer is very high $\left(\sigma_{f i k 1}\right)$, and that of the imperfect one - low $\left(\sigma_{f i k 3}\right)$. Mixer under operation constantly wears-out (blades, fretting and fastening elements wear-out and break) and this only increases the actual values of construction homogeneity estimes $\sigma_{f i k}$. Mixing kinetics analyzed by papers $[16,22]$ helps to bet- ter understand complexity of this process and its significance to mix quality.

It has been proved that sand, fine-grained and medium-grained substances shall be ,dry" mixed for 15 seconds and "wet" (with bitumen) mixed for additional 3060 seconds in asphalt concrete mixing machines with forced mixing mixers [23]. The shortest mixing time in substance mixers of the most perfect computerized asphalt concrete mixing machines shall be $45-60$ seconds [24], i.e., always exceed $30 \mathrm{~s}$.

The actual homogeneity estimate $\sigma_{f i}$ of $i$ component quantity of asphalt concrete mixture could be compared with maximum possible non-homogeneity estimate $\sigma_{\max i}$. The highest non-homogeneity of a mineral component is at 0 mixing of dozed mineral substances. Its estimate $\sigma_{\max i}$ is calculated by the theoretical formula

$$
\sigma_{\max i}=\sqrt{\mu(100-\mu)},
$$

$\mu-\operatorname{mix}$ grain full pouring-out per through a control sieve for mass $\%$.

When mixer quality estimate is calculated $[25,26]$, if $\sigma_{f i k}$ is replaced by $\sigma_{\max i}$ calculated according to formula (5), their values would be very high. For example, when $\mu=50 \%$, then $\sigma_{\max \max }=50 \%$, when $\mu=20$ or $80 \%$, then $\sigma_{\max }=40 \%$, when $\mu=10$ or $90 \%$, then $\sigma_{\max }=30 \%$ ) and would differ by some-teen or some tens of times from actual values $\sigma_{f i}$ obtained by experiments. Upon dividing $\sigma_{f i k}$ by $\sigma_{\max i}$ very low relative values would be obtained and they would not differ much for an imperfect, medium perfection and perfect mixers, thus making this estimate very ,insensitive" and therefore unsuitably reflecting mixing quality. No scientific proof exists on lowest possible average quadratic deviation for each component quantity $\sigma_{i \min }$. Theoretically it may be 0 , but there are no practical solutions as to how zero or close to zero value of it could be achieved. Actual asphalt cover mix homogeneity may not be determined by theoretical calculations. It may be determined only by taking a required number of individual samples in certain quantities and by analyzing each of them individually. If asphalt concrete mix is homogeneous in mixture, then there are no tolerances in 


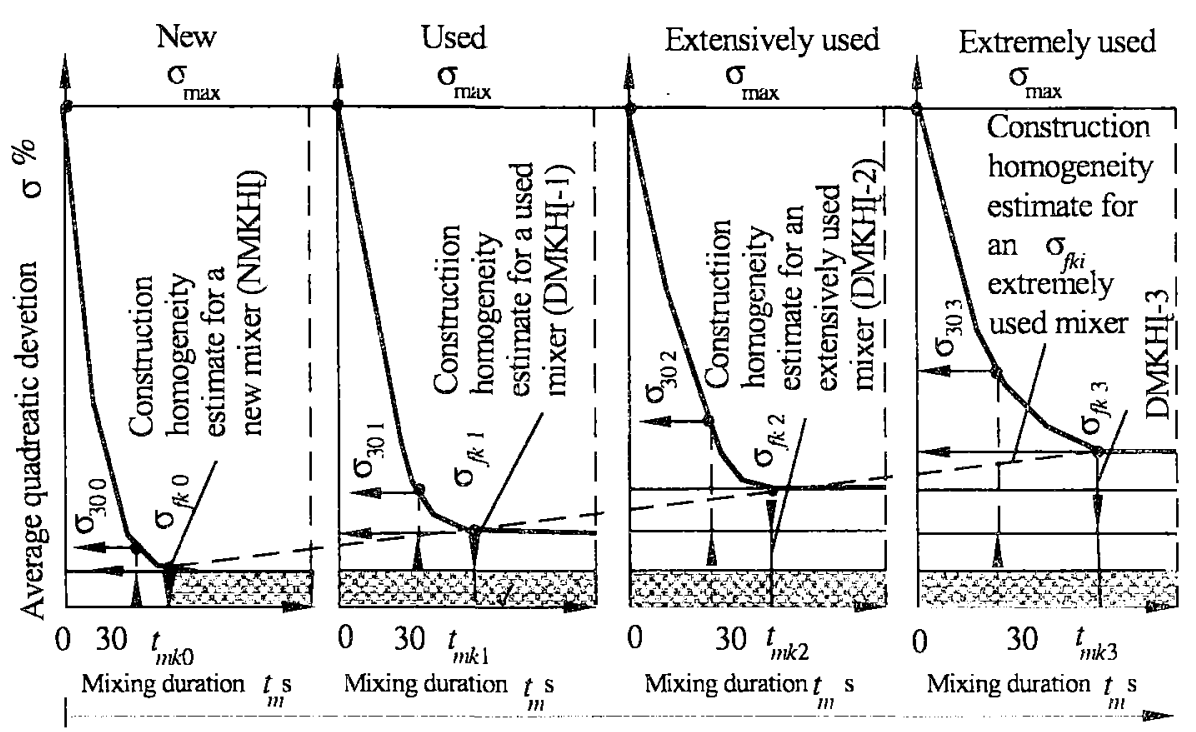

Fig 6. The dynamics of construction homogeneity reduction of the mixing equipment when the expoitation duration of asphalt concrete mixing equipment increases and deteriorated elements are not repaired

taking its samples but there are tolerances for test of bitumen extraction and sieving the mineral part with control sieves, which tolerances do not allow obtaining $\sigma_{f i k}=0$ and $\sigma_{30 i}=0$.

A certain lowest construction homogeneity demonstrated by the ordinate of the stroked-up area $\sigma_{f k 0}$ (Fig 6) is typical for an unused (new) mixer of each different construction. Upon mixer operation, due to constant wear of its elements construction homogeneity value of the estimate $\sigma_{f i k}$ increases. The difference $\Delta \sigma_{f i}$ between the estimate $\sigma_{30 i}$, obtained after mixing substances for 30 . seconds $\left(t_{30}\right)$, and construction homogeneity estimate $\sigma_{f i k}$ increases, as well:

$$
\Delta \sigma_{f i}=\sigma_{30 i}-\sigma_{f i k} .
$$

The more mixer is wom, the greater this difference is.

As far as minimum possible average quadratic deviation values $\sigma_{i \min }$ of each component quantity, which values are subject to characteristics of a specific mixer, are not known, these values may not be used to assess quality of an asphalt concrete mixing machine by mix. homogeneity. It leads to issue that parameters determined by the "settled" process or at least one of such stable parameters are the most suitable for such purpose, for example, homogeneity obtained after mixing for 30 seconds and expressed by the estimate $\sigma_{30 i}$.

\section{Measures to Improve Revolving-Blade Mixer Reli- ability}

Upon analyzing wearing-out elimination methods for revolving-blade mixers, as well as their reliability im- provement methods it may be stated that the following measures may be practically applicable:

- To reduce impact loads and starting loads of revolver-blade mixers it is expedient to use elastic centrifugal coupling with two rigidity modes [27, 28], which shall be calculated according to the value of torsion moment transmitted for basic operational and impact, as well as starting modes. Parameters of a cylinder elastic spring of the coupling shall be optimized by all operational and overload criteria, at the same time providing for thermal processing of elastic elements and the coupling material, as well;

- To restore worn-out blades by welding them with special wear-resistant substances. One of methods represents covering restored blades surface with hard alloys. As far as blade wearing-out level is different for various blade surfaces, full surface covering with hardening alloys of new blades is not expedient.

Most often chromium by-eutectic cast iron is used for blade production, with hardness (44...50) HRC. By fusing mixer blades with standard and experiment alloys $[7,8]$ hardness $(50 \ldots 66) \mathrm{HRC}$ is achieved. Thus the resistance of welded blades exceeds the standard one by $1,5 \ldots 2$ times [8]. Tests have demonstrated that the quality of mix produced may be increased approximately twice applying special wear-resistant materials for asphalt concrete mixer blade welding. This technical solution prolongs continuous mixer operating time by 1,5 to 3 times subject to the type of welding substances used, at the same mixing rate and the same granulometric mix composition in all cases.

Welding process is neither cheap nor simple. It needs special equipment and many metal processing procedures. Blades may be produced of wear-resistant, but much more 
expensive alloyed steel grades. Such reliability improvement measure for revolving-blade mixers is inexpedient, as far as blade resource insignificantly exceeds welded blade resource. Blades may be produced of low-alloyed steel grades, and after their thermal processing, optimum tempering temperature may be used to make them wearresistant. This process is inexpensive and may be performed under repair workshop conditions. Production of thicker blades may be recommended. Even metal structure in all cross-sections is hard to achieve this way. Due to this reason this solution looses its practical importance, as far as blades have to be demounted for tempering or other type of thermal processing. Producing thicker blades from alloyed steel has no point, as well, due to their high price.

One of the most important quality indicators of produced asphalt concrete or cement concrete mix is represented by its granulometric composition selected by calculating substance mass and is checked by laboratory testing of various samples. Optimum granulometric composition of designed mix shall be realized in its industrial production. When mixing the mix with continuous granulometric composition by a forced mixer, there always are grains most often sticking between the blade end and the mixer bottom. Changing the distance between the blade end and the mixer bottom subject to granulometric composition (grade) of the mix produced is unreasonable. The distance is minimum for a new mixer, but with mixer wearing this gap constantly increases. Therefore grains of various diameters may get stuck in the same mixer gap, which grains may not be removed, otherwise optimum granulometric mix composition would be distorted and its characteristics would be made worse.

In order to avoid grain sticking between blades and a mixer bottom for any grade of mix under production, this gap may be increased up to the coarsest grain's diameter. But such solution to this technical problem would cause formation of inert non-mixed grain zone at the mixer bottom and homogeneity of mix produced would be significantly reduced. Using a mixer with a very wide gap between the blade end and the fretting, it is reasonable to fasten a pivot- or plate-form „agitator" at the blade end. Such additional element would constantly agitate the forming non-mixed zone, grains from which would be brought back to the active mixing zone and the mix would be fully mixed within a short time, and grains would not get stuck and would not be crushed between blades and bottom.

\section{Conclusions}

1. The main causes for wearing-out of a revolvingblade mixer are:

- Loads occurring at transmission starting;

- Accidental occurrence of hard grains together with mixed substance;

- Intensive wearing of blades and bottom.
2. Homogeneity of produced asphalt concrete mix on the basis of which asphalt concrete mixer quality is assessed is subject to distribution uniformity of mixed components throughout the mix.

Homogeneity of asphalt concrete mix is not regulated by normative documents, therefore no standard and permissible values of its estimate are known, against which the actual component homogeneity indicator could be compared at any substance mixing time. $t_{m}=30 \mathrm{~s}$ could be considered as the fixed homogeneity mixing time. When mixing substances sufficiently long, such time $t_{m}$ is achieved when average quadratic deviations of mixture component quantities $\sigma_{f i}$ in asphalt concrete mix do not reduce any more. The lowest $\sigma_{f i}$ values subject only to the mixer construction, wear level of its elements and operation mode are reflected by construction homogeneity estimate $\sigma_{f i k}$.

3 . Revolving-blade mixer reliability may be increased using a vibro-impact and overioad suppressing element in the transmission system - an elastic centrifugal coupling with two rigidity modes, by welding wornout blades with special wear-resistant substances, by producing blades of wear-resistant, but much more expensive alloyed steel grades, by producing blades of low alloyed steel grades but with their thermal hardening, by producing thicker blades and by using blades with „agitators"

\section{References}

1. Brykov, N. N.; Popov, S. N. Influence of structure of the alloys of asphalt mixing plants on the resistance of amortization. Constructing road machines (Cnpoumenbнодорожсые маиины). 1991, No 2, p. 18-21 (in Russian).

2. Balovnev, V. I.; Ermilov, A. B.; Novikov, A. N. Road- constructing machines and equipment (Дорожностроительные матиины и оборудование). Moscow: Маchine construction, 1998, 384 p. (in Russian).

3. Bardajev, S. B.; Timofejev, V. A. About influence of crushing and abrasion of firm particles on power of impeller of mixers. Constructing and road machines (Cmpoumenbroдорожные машины), 1982, No 4, p. 67 (in Russian).

4. Volkov D.P., Alioshin N.I., and others. Constructing machines (Строительные машины). Moscow: Vysšaja škola, 1988, p. 252 (in Russian).

5. Novikov, A. N. Plants for preparing of asphalt concrete mixture (Установки для приготовления асфальтобетонной смеси). Moscow: Vysšaja škola, 1977, 232 p. (in Russian).

6. Novikov, A. N. Asphalt mixing plants (Aсфальтосмесиетельные установки). Moscow: Vyš̌aja škola, 1987. 203 p. (in Russian).

7. Semiontsov, N. Z. Amortization of asphalt mixer blades. Motor roads (Aвmonoбuльные dopozu). 1975, № 7, p. 2930 (in Russian).

8. Serniontsov, N. Z. Increasing of serving term of asphalt mixer blades. Motor roads (Автомобильные dороги). 1979, No 12, p. 27-28 (in Russian). 
9. Timofeev, V. A.; Solomatin V. I.; Goldsstein, A. J. Research of functioning of impeller mixers. Constructing- road machines (Cпроительно-дорожные маиииы), 1972, No 3 , p. 26-28 (in Russian).

10. Trifonov, V. P.; Sokolov, B. F. Experimental research of the process of mixing asphalt-concrete mixtures. Motor roads and artificial constructions in North and West, R.S.F.S.R. (Экспериментальное исследование процесса псрсмсшивания асфальтобетонных смесей. Соверші. автомоб. дорог и искусств. сооруж. на Сев.--Зап. РСФСР), Leningrad, 1987, p. 139-145 (in Russian).

11. Deshpande, V. S.; Cebon, D. Uniaxial experiments on idealized asphalt mixes. Journal of Materials in Civil Engineering, 2000 August, No 3, p. 262-271.

12. Obaidat, M. T., Al-Masaeid, H. R., Gharaybeh, F. An innovative digital image analysis approach to quantify the percentage of voids in mineral aggregates of bituminous mixtures. Can. I. Civ. Eng., 1998, 25, NRC Canada, p. 10411049.

13. Lee, H.-I.; Daniel, I. S.; Kim, Y. R. Continuum damage mechanics - based fatigue model of asphalt concrete. Journal of Materials in Civil Engineering, $2000 \mathrm{May}$, Vol 12, No 2, p. $105-112$.

14. Bracegirdle, P. E. A new process and apparatus for making asphait concrete. Transp. Res., 1984, No 986, p. 22-26.

15. Rousselin, R.-I;; Baroux, R.; Charonnat, Y. Application des traceurs pour l'etude du malaxage des materiaux de construction. Bulletin de liason des laboratories des Ponts et Choussees. Nov.-Dec. 1985, No 140, p. 113-118.

16. Leclerc, I.-P.; Muhr, H.; Findeling, C.; Terriere, I.; Charannat, Y. Modelisation de l'ecoulement de l'eau et du filler dans un malaxeur industriel et determination de son pouvoir de lissage. Bulletin des laboratories des Ponts et Chaussees, LCPC, 1996 janv. -fevr, No 201, p. 5-15.

17. Boss, I.; Knapik, A. T.; Wegrzyn, M. Segregation of heterogeneous grain systems during mixing in static mixers. Bulk solids Handl, 1986, 6, No 1, p. 145-149.

18. Salter, G. F.; Farnish, R. I.; Bradley, M. S. A.; Burnett, A. I. Segregation of binary mixtures of particles during the filling of a two- dimensional representation of a hopper. Proc. Instn. Mech. Engrs., 2000, Vol 214, Part. E, p. 197-208.

19. Guideline of construction R 35-01. Asphalt concrete and grit cover of automobile roads (Statybos rekomendacijos R 35-01. Automobilių kelių asfaltbetonio ir žvyro dangos). Vilnius: LAKD. 2001. 117 p. (in Lithuanian).
20. Petkevičius, $K$. The perspectives of the perfections of road freightage in the quality improvement of asphalt concrete pavements. Research work of higher educational establishments of Lithuanian SSR. Automobile transport. Perfecting the territorial carriages by road (Научные тр. высш. науч. заведений Литовской ССР. Автомобильный транспорт, № 4. Совершенствование территориальных автомобильных перевозок). Vilnius, 1989, p. 154-165 (in Russian).

21. Christauskas, J, Effect of duration of asphalt concrete mixing on its homogeneity. Information of higer educational establishments. Construction and architecture (Известия вузов. Строительство и архитекгура), 1982, № 12, p. 117 119 (in Russian).

22. Moneron, P. Controle de la teneur en liant des eurob's Bulletin de liaison des laboratores des Ponts et Chaussees. LCPC. 1995, Sept.-Oct. No 199 , p. 55-62.

23. Manual of construction of asphalt concrete road coverings (Руководство по строительству дорожных асфальтобетонных покрытий). Moskow: Transport, 1978. 192 p. (in Russian).

24. Bituminous mixtures in road construction. Edited by Robent N. Hunter. London: Thomas Telford. 1997. 441 p.

25. Sivilevičius, H. Criteria and methodology of complex evaluation of bituminous concrete plant quality. Civil Engineering (Statyba), 2001, Vol VII, No 3, p. 213-223 (in Lithuanian).

26. Sivilevičius, H. Substantiation of complex evolution criteria of asphalt paving plant quality and application of methodology in practice. Journal of Civil Engineering and Management, 2002, Vol VIII, Suppl 2, p. 112-125 (in Lithuanian).

27. A.c. 542043 SSSR, F 16 D 43/14. Elastic center coupling/ A- P. K. Kavolelis, B. P. Spruogis, J. I. Jurevicz, and others. Published in 1977.

28. Spruogis, B. The devices of transmission and stabilization of rotary motion. Monograph (Устройства для передачи и стабилизации вращательного движения). Vilnius: Technika, 1997, 476 p. (in Russian). 